\section{Callosity of ankles among people with the habit of sitting with crossed legs: a cosmetic problem}

\section{Mohammad Omidian, Ehsan Omidian \\ University of Medical Sciences, Ahvaz, Iran}

\begin{abstract}
Many people living in developing countries still prefer to sit on the carpet or uncarpeted floor, and many times they sit in a cross legged position. Continuous rubbing and friction of the ankles over the carpet or the plain hard surface may cause callosity of the ankles. This can cause a cosmetic problem. We describe a case series of ankle hyperkeratosis referred to our outpatient clinic in Ahwaz in the south west of Iran from 2005-2010. These patients had localized hyperkeratosis on two ankles or the front of ankles. This article aims to help the clinician become more familiar with the morphological characteristic of this problem which may occur in people of Eastern origin.
\end{abstract}

\section{Introduction}

Callosity is a plaque of hyperkeratosis caused by repeated friction and/or pressure. A corn is a sharply demarcated callosity occurring over a bony prominence. This is usually on the hand or foot and is painful. ${ }^{1}$ Repeated friction or trauma on the extensor surfaces, such as elbows, knees and also ankles, cause hyperkeratosis. ${ }^{2,3}$ People living in developing countries still have the habit of sitting in a cross legged position on a plain, hard surface, rather than using furniture. Ankle callosity and hyperkeratosis is a common finding among subjects with this habit and these cause a cosmetic problem. We describe a case series of ankle hyperkeratosis among people with the habit of sitting cross legged.

\section{Case Report}

The case series consisted of 148 cases (112 women and 36 men) with a mean age of 32 years (age range 18-57 years old) referred to our private clinic and Imam Hospital, Ahwaz, in the south west of Iran from 2005 to 2010 . All cases had the habit of sitting cross legged on the carpet or uncarpeted hard surface and not on the furniture. In this position, their lateral ankles touched the carpet or the plain, hard surface. This bilateral contact resulted in repetitive minor trauma directly associated with the patients' habit of sitting cross legged. There were no other symptoms. Patients were referred for cosmetic reasons and almost none of the patients knew the cause. Some of the patients, while praying, touched the carpet with their knees, the back of the feet and one side of the external ankle. Clinical examination showed localized hyperkeratosis. This was well defined and of a dark color with minimal scaling on the external ankles or on the front of the ankles (Figures 1-4). Table 1 shows the number of cases in each age group; the condition is most common in the 31-40 year old age group.

\section{Discussion}

Many people, especially non-Westerners, who usually sit on a plain, hard surface in a cross legged position, or who sit on their knees, may develop callosities on prominent areas of their bodies, such as their ankles or dorsa-lateral aspects of their feet. The knees may also be involved. These conditions develop as a result of continuous and repeated friction of the prominent areas. They are usually associated with hypermelanosis, and roughening of the lesions and their surroundings..$^{3-4}$ In this

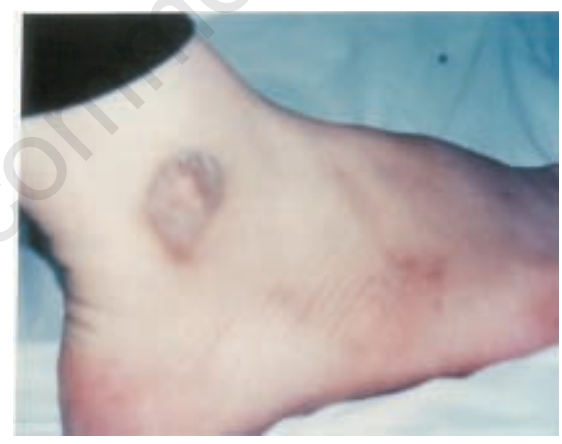

Figure 1. Ankle hyperkeratosis (callosity). (Photograph courtesy of Dr M Omidian.)

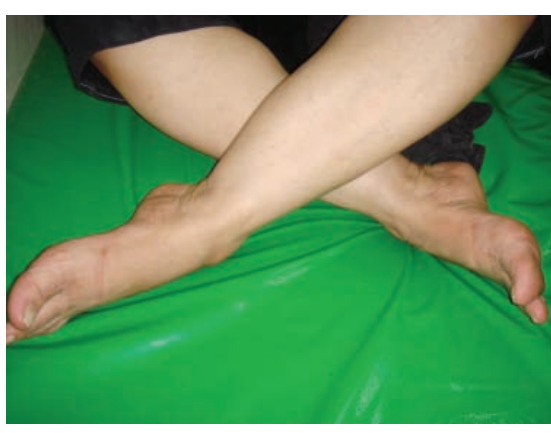

Figure 2. Cross legged position. (Photograph courtesy of Dr M Omidian.)
Correspondence: Mohammad Omidian, Dept. of Dermatology, Imam Khomeini Hospital, Iran.

E-mail:momidian@yahoo.com

Key words: ankles, hyperkeratosis, callosity, crossed legs, habit.

Received for publication: 14 November 2011.

Revision received: 30 August 2011

Accepted for publication: 30 August 2011.

This work is licensed under a Creative Commons Attribution NonCommercial 3.0 License (CC BYNC 3.0).

(C) Copyright M. Omidian and E. Omidian, 2011 Licensee PAGEPress, Italy

Dermatology Reports 2011; 3:e24 doi:10.4081/dr.2011.e24

Table 1. Case numbers according to age group.

\begin{tabular}{lc} 
Age years & N. patients \\
$0-20$ & 8 \\
$21-30$ & 10 \\
\hline $31-40$ & 57 \\
$41-50$ & 41 \\
\hline $51-60$ & 18 \\
$61-70$ & 14 \\
\hline
\end{tabular}

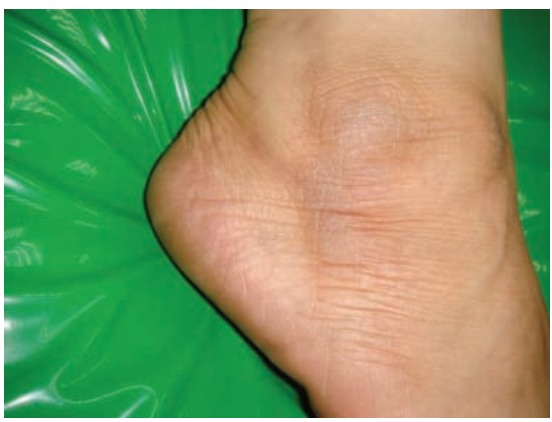

Figure 3. Ankle hyperkeratosis on the ankle and the lower front of the ankle (callosity). (Photograph courtesy of Dr M Omidian.)

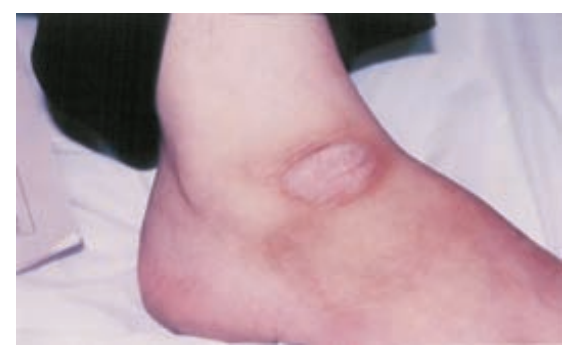

Figure 4. Localized hyperkeratosis (callosity) in the front of the ankle. (Photograph courtesy of Dr M Omidian.) 
case series, we report 148 cases over a period of five years who asked for treatment for cosmetic reasons. This shows that the condition is frequently seen and can be a cosmetic concern. Some general physicians and almost all the patients are not informed about its etiology. Our cases showed asymptomatic localized hyperkeratosis on the ankles due to chronic pressure and friction. Both frictional stress and family history may play a role in the pathogenesis of this condition. ${ }^{3}$ Hyperkeratosis usually takes some years to develop and is a result of repeated trauma to the skin from friction and pressure. ${ }^{4}$ In our series, there was no evidence of hereditary disorders, such as keratoderma or systemic factors producing the hyperkeratosis. It is believed to be due to chronic mechanical stimulation of the ankles. The characteristic yoga sitting position on plain, hard floors exerts mechanical stress because of repeated and prolonged pressure. ${ }^{5}$ Calluses and corns on the feet are usually the result of deformity sometimes associated with dynamic damage to foot function. They are made worse or even caused by unsuitable footwear and are usually painful., ${ }^{1,6}$ The cases in our series did not have any symp- toms, and limb formation and function was normal. The condition could not be related to footwear but patients had a habit of sitting with one foot tucked under their body or in a cross legged position. These cases did not have any history or clinical feature of psoriasis or eczema. Hyperkeratosis is a normal protective response of the skin. It becomes pathological when the callus or corn grows so large that it becomes the source of symptoms. ${ }^{2}$ On the back of the foot, factors provoking callosities include footwear and a habit of sitting with the foot tucked under the body with or without a prominent underlying talus. ${ }^{7,8}$ It is most common in the 31-40 year old age group because the condition is progressive. It starts in childhood and after many years the callus or the corn becomes thicker. The condition was more common in women than men, because in our geographical area most of the women are housewives who work at home and sit on the carpet.

In conclusion, clinicians dealing with patients who have the habit of sitting cross legged should consider the importance of ankle callosity for a differential diagnosis from psoriasis, eczema and keratoderma.

\section{References}

1. Singh D, Bentley G, Trevino SC. Callosities, corn and calluses. BMJ 1996; 312:1403-6.

2. Denise B and Freeman DPM. Corn and calluses from mechanical hyperkeratosis. Am Fam Physician 2002;65:2277-80.

3. Krishnamurthy S, Sigdel S, Brodell RT. Frictional asymptomatic darkening of the extensor surfaces. Cutis 2005;75:349-55.

4. Wahlberg JE. Occupational hyperkeratosis in carpet installers. Am J Ind Med 1985; 8:351-3.

5. Verma SB, Wollina U. Callosities of cross legged sitting: Yoga sign-an under-recognized cultural cutaneous presentation. Inter J Dermatol 2008;47:121-4.

6. Dishan S, George B, Saul GT. Callosities, corn, and calluses. BMJ 1996;312:1403-6.

7. Cox NH, Finaly AY. Crossed-Leg callosities. Acta Derm Venereol 1985;65:559-61.

8. Verbov JL, Monk CJE. Talar callosity: a Lttle-recognised common entity. Clin Exp Dermatol 1991;16:118-20. 